\title{
International variation in the management of severe COVID-19 patients
}

\author{
Elie Azoulay ${ }^{1 *}$ D , Jan de Waele 2 , Ricard Ferrer ${ }^{3,4}$, Thomas Staudinger ${ }^{5}$, Marta Borkowska², Pedro Povoa ${ }^{6}$, \\ Katerina Iliopoulou ${ }^{7}$, Antonio Artigas ${ }^{8}$, Stefan J. Schaller ${ }^{9}$, Manu Shankar-Hari ${ }^{10}$, Mariangela Pellegrini ${ }^{11,12,13}$, \\ Michael Darmon ${ }^{1}$, Jozef Kesecioglu ${ }^{14}$ and Maurizio Cecconi ${ }^{15}$
}

\begin{abstract}
Background: There is little evidence to support the management of severe COVID-19 patients,

Methods: To document this variation in practices, we performed an online survey (April 30-May 25, 2020) on behalf of the European Society of Intensive Care Medicine (ESICM). A case vignette was sent to ESICM members. Questions investigated practices for a previously healthy 39-year-old patient presenting with severe hypoxemia from COVID-19 infection.

Results: A total of 1132 ICU specialists (response rate 20\%) from 85 countries (12 regions) responded to the survey. The survey provides information on the heterogeneity in patient's management, more particularly regarding the timing of ICU admission, the first line oxygenation strategy, optimization of management, and ventilatory settings in case of refractory hypoxemia. Practices related to antibacterial, antiviral, and anti-inflammatory therapies are also investigated.
\end{abstract}

Conclusions: There are important practice variations in the management of severe COVID-19 patients, including differences at regional and individual levels. Large outcome studies based on multinational registries are warranted.

Keywords: Coronavirus, Acute respiratory distress syndrome, Viral infection, Remdesivir

\section{Background}

There is little evidence to support the optimal management of severe COVID-19 patients [1,2]. To document whether there is a variation in practices, we performed an online survey (April 30-May 25, 2020) on behalf of ESICM.

\section{Methods}

In this online survey, a case vignette (https://www.surveymonkey.com/r/F2FFC6S) was sent to ICU specialists who are members of ESICM. Questions investigated

\footnotetext{
*Correspondence: elie.azoulay@aphp.fr

'Médecine Intensive et Réanimation, Department of the St-Louis Hospital,

APHP, Hôpital Saint-Louis, Paris University, 1 avenue Claude Vellefaux, 75010 Paris, France

Full list of author information is available at the end of the article
}

practices for a previously healthy 39-year-old patient presenting with severe hypoxemia from COVID-19 infection (Table 1). The 85 participating countries were grouped into 12 different regions [3]: continuous variables are described as median (interquartile range [IQR]) and are compared between groups using the non-parametric Wilcoxon rank-sum test. Categorical variables are described as frequency (percentages) and are compared between groups using Fisher's exact test. Statistical analyses were performed with $\mathrm{R}$ statistical software, version 3.4.3 (available online at http://www.rproject.org/). A $p$ value $<0.05$ was considered significant.

C C The Author(s). 2020 Open Access This article is licensed under a Creative Commons Attribution 4.0 International License, which permits use, sharing, adaptation, distribution and reproduction in any medium or format, as long as you give appropriate credit to the original author(s) and the source, provide a link to the Creative Commons licence, and indicate if changes were made. The images or other third party material in this article are included in the article's Creative Commons licence, unless indicated otherwise in a credit line to the material. If material is not included in the article's Creative Commons licence and your intended use is not permitted by statutory regulation or exceeds the permitted use, you will need to obtain permission directly from the copyright holder. To view a copy of this licence, visit http://creativecommons.org/licenses/by/4.0/ The Creative Commons Public Domain Dedication waiver (http://creativecommons.org/publicdomain/zero/1.0/) applies to the data made available in this article, unless otherwise stated in a credit line to the data. 


\section{Results}

Response rate was $20 \%$ ( $N=1132$ intensive care (ICU) specialists from 85 countries, including 1001 complete answers). Respondents (median 45 years [IQR, 3953], 34\% women) were from Middle Europe (25\%), South Europe (23\%), the United Kingdom (UK) (12\%),
South America (9\%), North Europe (8.1\%), Eastern Europe (5.3\%), Middle-East (5\%), North America (4.7\%), Asia (3.3\%), India (2.7\%), Australia-New Zealand (1.3\%), or Africa (0.6\%); $54 \%$ were living in a large city ( $>1$ million inhabitants), and $55 \%$ were working in university-affiliated hospitals. The median

Table 1 Distribution of the responses to the case vignette

1. Admission to the ICU of a previously healthy 39-year-old man with severe COVID-19

Direct admission to the ICU

$55 \%$

Admission in an intermediate care unit

Delayed admission to the ICU because of lack of bed

$1.3 \%$

Patient stays in the emergency department

$0.8 \%$

Patient admitted in the wards $8.8 \%$

\section{Initial oxygenation strategy}

I increase the oxygen flow to $15 \mathrm{l} / \mathrm{min}$ keeping the face mask

I change the mask for a Venturi mask

I start CPAP or noninvasive ventilation

I start high flow nasal oxygen

$47.1 \%$

I intubate the patient right away

$7.4 \%$

I add prone positioning on spontaneous breathing

3. Optimizing oxygenation in a patient with a PF ratio of $844 \mathrm{~h}$ after intubation

I will give neuromuscular blockade for 24-48 h

$50.9 \%$

I increase and titrate PEEP to optimize recruitment

$61.4 \%$

I prone the patient immediately

I am considering ECMO immediately

$4.7 \%$

Let us wait a little bit

\section{Regarding the initial antibiotics}

All my patients receive a broad anti-bacterial agent

I only give broad anti-bacterial agent to febrile patients

I only give broad anti-bacterial agent if CRP or PCT are high

I only give broad anti-bacterials to patients with structural lung diseases

I never give broad anti-bacterial agent in severe viral infections

\section{Regarding initial anti-viral therapy, several options are possible}

The level of evidence is so low that there is nothing I can give

I prescribe (hydroxy)chloroquine

I prescribe lopinavir/ritonavir

I prescribe remdesivir

I prescribe another anti-viral drug

\section{Are you starting an anti-inflammatory therapy?}

No

Yes, complement blockade 
(IQR) number of ICU beds was increased from 20 (11-36) to 35 (20-60) during the pandemic surge.

As the patient had 88 (peripheral oxygen saturation) $\mathrm{SpO}_{2}$ on $9 \mathrm{l} / \mathrm{min}$ of oxygen, direct ICU admission was reported in 56\% (30-90\%) of the respondents, with significant variation across regions (Fig. $1, P<0.0001$ ). Most intensivists not directly admitting patients to the ICU would admit them to an intermediate care unit managed by intensivists. However, the issue of bed availability was reported in South Europe (4.5\%), South America (2.9\%), Scandinavia (1.6\%), Middle Europe (1.6\%), and the UK (1.1\%). Should the patient be not admitted to the ICU, a rapid response team would be involved in $29 \%$ of the cases, the ICU specialist would make the outreach her/himself in $24 \%$ of the cases, or an ICU nurse would be involved in $7 \%$ of the cases. In all other cases, ward or ED physicians would manage the patients. Direct ICU admission was significantly associated with baseline number of ICU beds $(22[12-40]$ vs. $18[10-30]$ beds, $P<0.0001)$ and with the number of COVID-19 patients managed (30 [11-52] vs. 38 [20-70] patients, $P=0.001$ ), as well as with management of patients in large cities $(56.9 \%$ vs. $49.6 \%, P=0.04)$.
Respondents were then asked about the first-line oxygenation strategy, which varied significantly across regions (Fig. 2, $P<0.0001$ ). First-line high flow nasal cannula (HFNC) was used by $22.9 \%$ of the respondents $(0 \%$ in Australia-New Zealand, 38\% in Eastern Europe). Noninvasive ventilation was used by $25.5 \%$ of the respondents $(5.4 \%$ in North America, $43.6 \%$ in the UK). Interestingly, $8 \%$ of the respondents were using first-line intubation ( $0 \%$ in Australia-New Zealand, $23 \%$ in Asia). Women less frequently initiated HFNC ( $32 \%$ vs. $42 \%, P=0.02)$. The availability of an intermediate care unit influenced the use of HFNC or non-invasive ventilation (NIV) $(32.8 \%$ vs. $21.7 \%, P=$ $0.03)$. Along this line, a higher number of ICU beds (24 (12-40) vs. $18(10-30)$ beds, $P=0.0009)$ was associated with the use of HFNC and NIV. Interestingly, $37.5 \%$ were using prone positioning in awake nonventilated patients. To assess whether HFNC or NIV should be continued, ICU specialists relied on $\mathrm{SpO}_{2}$ (85.7\%), respiratory rate $(71.4 \%)$, followed by dyspnea (47.1\%), and comfort (45.4\%). Criteria for intubation included clinical signs of respiratory distress (94\%), high oxygen flow to maintain a $\mathrm{SpO}_{2}$ of $95 \%$ (33.5\%), or low $\mathrm{SpO}_{2}$ only (25.6\%).

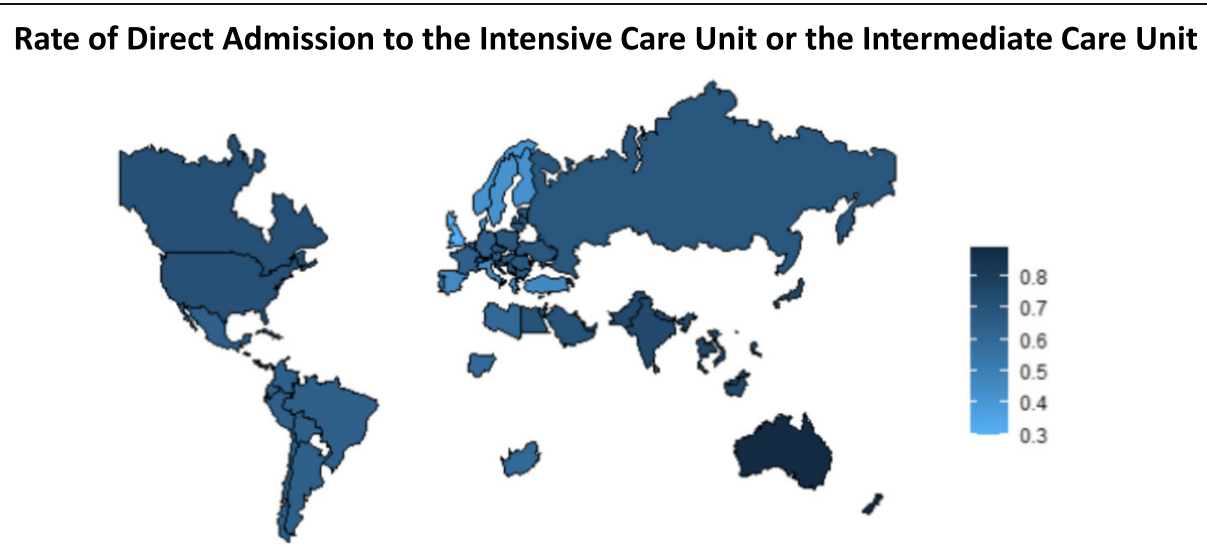

Rate of Direct Admission to the Intensive Care Unit
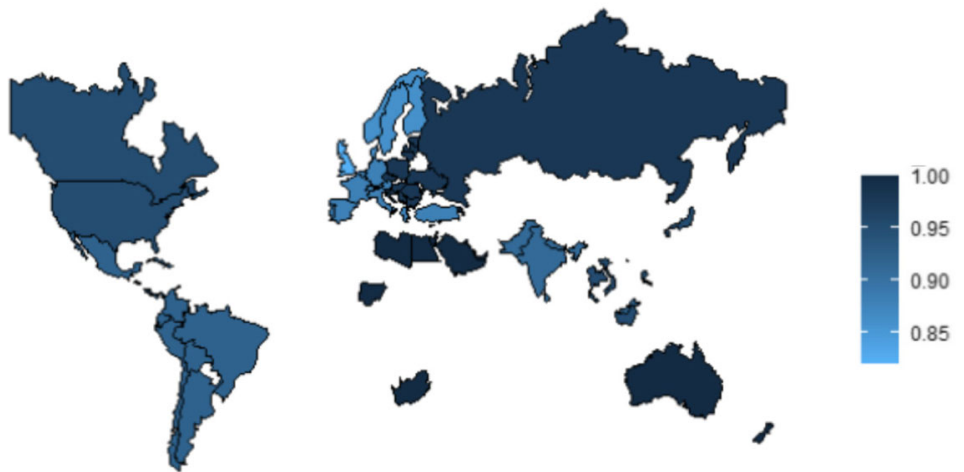

Fig. 1 World map displaying practice variations across regions regarding direct admission to the ICU or the intermediate care unit 
Following intubation, the patient had a partial pressure of oxygen/fraction of inspired oxygen $(\mathrm{P} / \mathrm{F})$ ratio of $84 \mathrm{mmHg}$. Although prone positioning (71.2\%) and neuromuscular blockade (59.7\%) were often used to optimize oxygenation, the practice varied significantly across countries. For instance, prone positioning was performed in $70-85 \%$ of the cases in Asia, India, Eastern Europe, Middle Europe, South America, South Europe, and the UK, whereas Africa, Australia-New Zealand, Middle East, North America, and Scandinavia were in the $50-70 \%$ range (Fig. 3, $P<0.0001$ ). Respondent's age was associated with the use of prone positioning $(46[39-54]$ vs. 44 [37-51] years, $P=0.007)$. Older respondent's age $(45$ [37-52] vs. $47[40-55]$ years, $P=0.0001)$, living in a large city $(54.2 \%$ vs. $46.8 \%, P=0.03)$, and a higher number of COVID-19 patients managed (35 [15-65] vs. $30[12-55]$ patients, $P=0.02$ ) were associated with the use of neuromuscular blockade.
Antibiotic prescribing was routine for all patients in $44.2 \%$ of the respondents and biomarker-guided in $36.5 \%$, without significant variation across regions. Routine antibiotics were more frequently used by respondents working in university-affiliated hospitals ( $48.3 \%$ vs. $40.9 \%, P=0.03)$ and those living in large cities $(49.3 \%$ vs. $40.2 \%, P=0.01)$. Biomarker-guided antibiotic therapy was less frequent in large cities (47.3\% vs. $57.4 \%, P=0.007)$. Regarding antiviral therapy, $48.9 \%$ reported not prescribing antivirals, $42.6 \%$ were giving hydroxychloroquine, $17 \%$ lopinavir-ritonavir, and 15\% remdesivir. Figure 4 displays significant variation in antiviral prescriptions across regions $(P<0.0001)$. Physicians not prescribing antivirals were older $(47[40-54]$ vs. $44[37-51]$ years, $P<0.0001)$, and more frequently men $(55.4 \%$ vs. $39.9 \%, P<0.0001)$. Conversely, those prescribing hydroxychloroquine were younger (43 [37-50] vs. 47 [40-54] years, $P<0.0001)$, and more frequently

\section{Use of Non-Invasive Mechanical Ventilation}
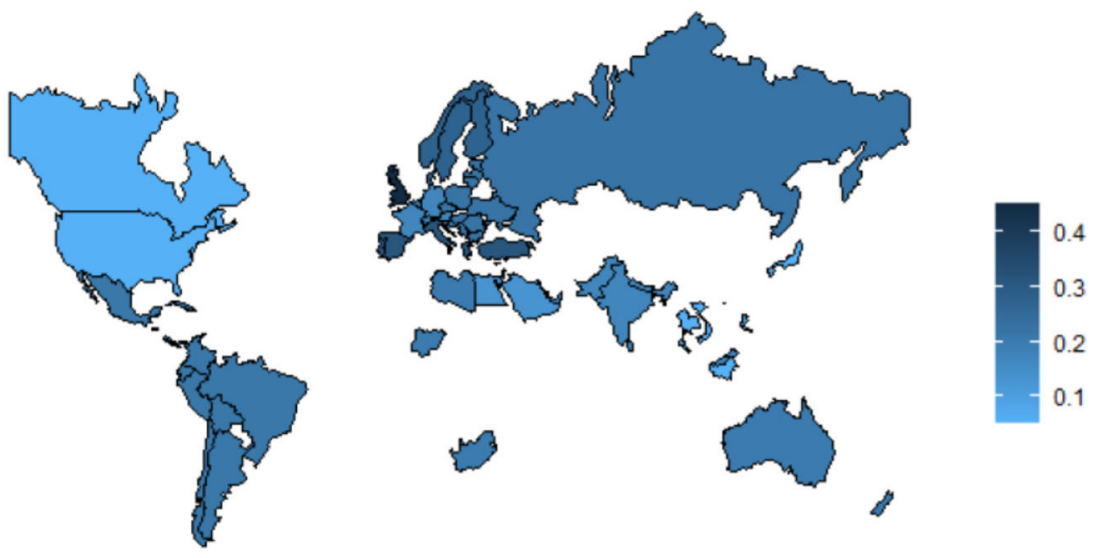

\section{Use of High Flow Nasal Cannula}
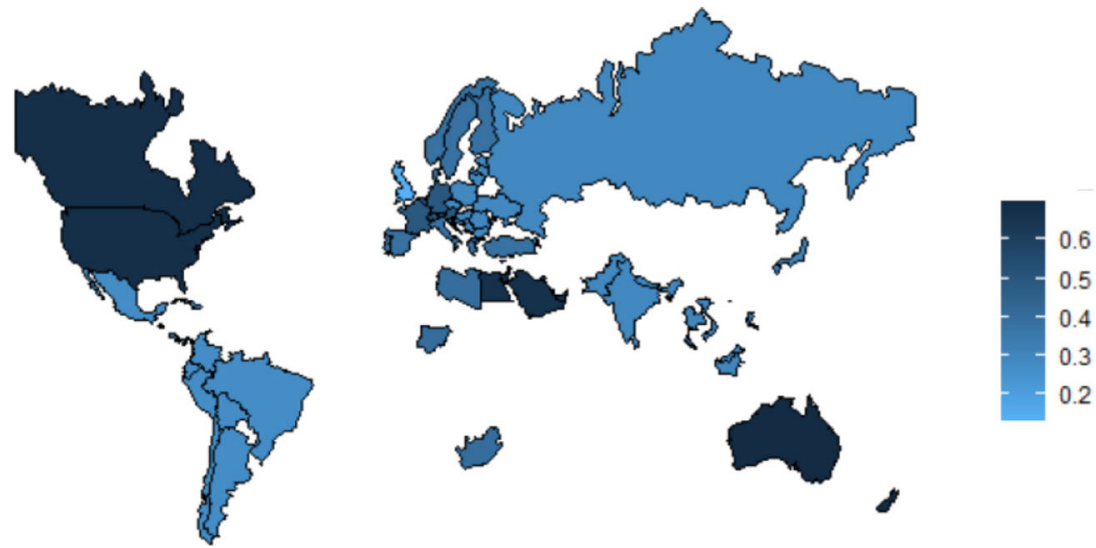

Fig. 2 World map displaying practice variations across regions regarding the use of noninvasive oxygenation strategies 


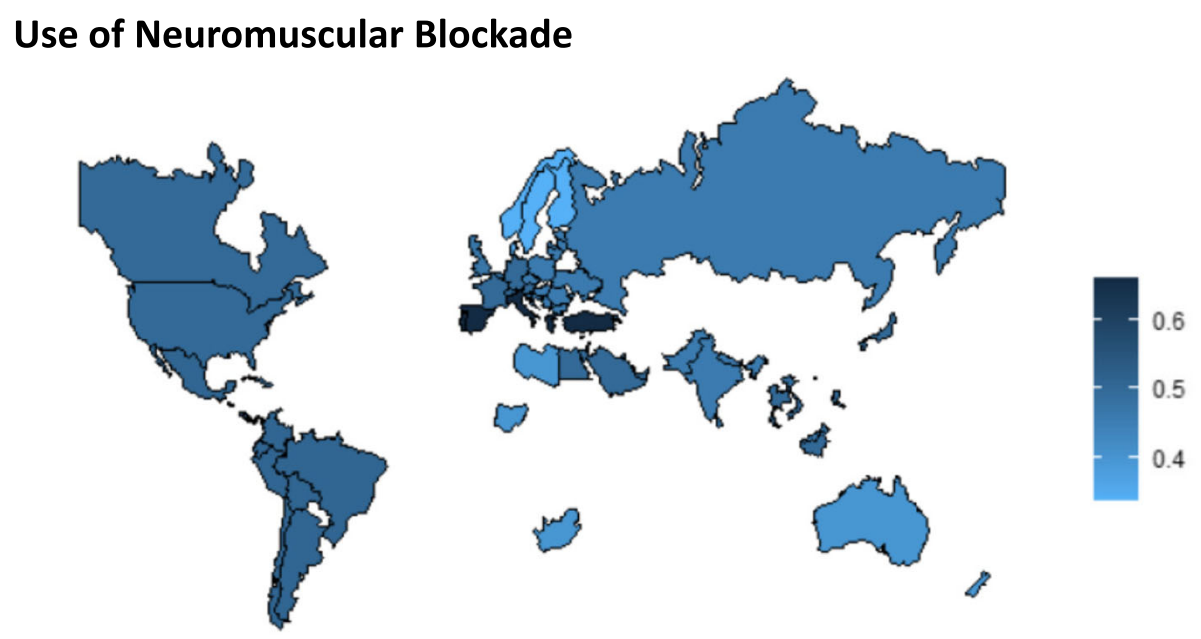

\section{Use of Prone Positioning}
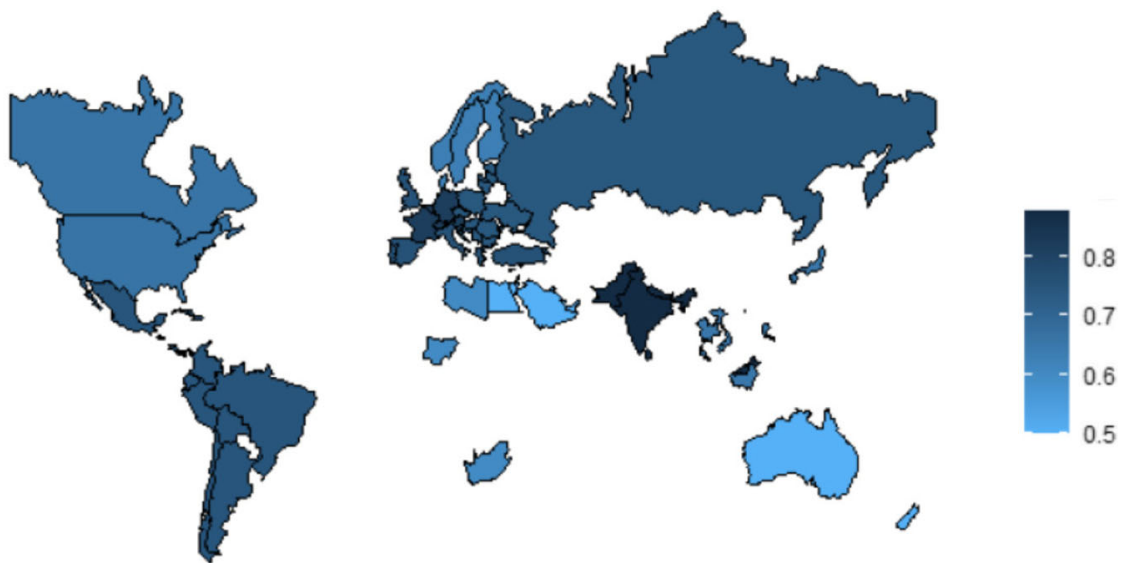

Fig. 3 World map displaying practice variations across regions regarding the use of neuromuscular blockades and prone positioning

women $(41.7 \%$ vs. $28.2 \%, P<0.0001)$. There was significant variation in the use of interleukin-6 (IL6)/IL-1 blockade or of corticosteroids across countries $(P<0.0001$ for both tests). Other collected variables were not associated with the use of antiinflammatory drugs.

\section{Discussion}

This survey highlights important practice variations in the management of severe COVID-19 patients, including differences at regional and individual levels. This illustrates that neither IDSA nor Surviving Sepsis Guidelines did recommend any of these treatments, but instead encouraged inclusion of patients into trials $[1,4,5]$. Since the publication of these guidelines, no more evidence has been made available to ascertain that these specific COVID-19 therapies should be included in the standard of care. Learning from this heterogeneity will not only raise hypothesis on optimal patient's management, but also serves as a tool to suggest personalized management for each clinical phenotype $[6,7]$.

This study has several limitations. First, the study suffers from a nonresponse bias of $80 \%$. Second, even though only physicians have responded, we cannot ascertain that all of them had the clinical expertise and the experience of managing COVID-19 patients. Last, questions about specific treatments did not take into account the fact that the level of evidence has changed over time.

\section{Conclusion}

As no management guidelines have allowed to guide practices for the COVID-19 pandemic, heterogeneous behaviors are reported. Large 


\section{Proportion of Respondents Considering No Antiviral Agent}
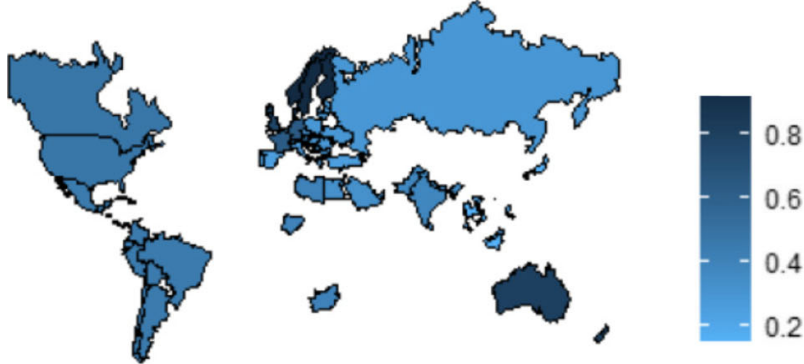

\section{Proportion of Respondents Considering Remdesivir}
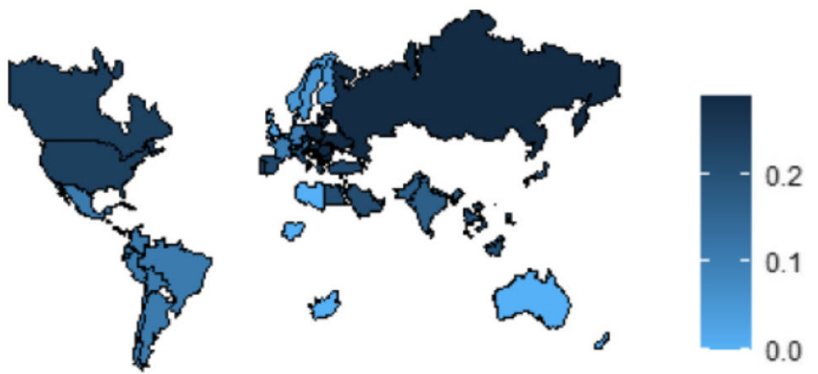

\section{Proportion of Respondents Considering Hydroxychloroquine}
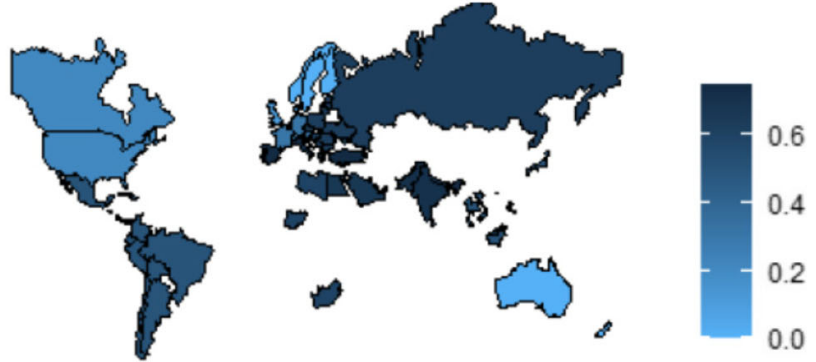

Fig. 4 World map displaying practice variations across regions regarding the use of antiviral agents

outcome studies based on multinational registries are warranted.

\section{Acknowledgements}

We are indebted to Dominique de Boom, Nicolas Vander Elst, and Guy Francois from the ESICM office for their fast and high-quality support to prepare this survey and its diffusion.

\section{Authors' contributions}

All authors contributed to the design, the development of the instrument, and interpretation of data. All authors have approved the submitted manuscript.

\section{Funding}

None

Availability of data and materials

Fully available upon request.

Ethics approval and consent to participate

All participants agreed online to complete the survey.
Consent for publication

All participants consented.

\section{Competing interests}

The authors declare no conflict of interest in relation to this survey.

\section{Author details}

'Médecine Intensive et Réanimation, Department of the St-Louis Hospital, APHP, Hôpital Saint-Louis, Paris University, 1 avenue Claude Vellefaux, 75010 Paris, France. ${ }^{2}$ Department of Critical Care Medicine, Ghent University Hospital, 9000 Gent, Netherlands. ${ }^{3}$ Shock, Organ Dysfunction, and Resuscitation Research Group (SODIR), Instituto de Investigación de Vall d'Hebron, Barcelona, Spain. ${ }^{4}$ Departmento de Medicina Intensiva, Hospita Universitario de Vall d́Hebron, Centro de Investigación Biomédica en Red (CIBER) de Enfermedades Respiratorias, Barcelona, Spain. ${ }^{5}$ Department of Medicine I, Intensive Care Unit, Medical University of Vienna, Vienna General Hospital, Vienna, Austria. ${ }^{6}$ NOVA Medical School, CHRC, New University of Lisbon, Unidade de Cuidados Intensivos Polivalente, Hospital de São Francisco Xavier, CHLO, Estrada Do Forte Do Alto Do Duque, 1449-005 Lisbon, Portugal. ${ }^{7}$ Hellenic Army, ICU Nurse Manager General Military Hospital, Athens, Greece. ${ }^{8}$ Critical Care Center, Sabadell Hospital, University Institute Parc Taulí, Autonomous University of Barcelona, Ciberes, Barcelona, 
Spain. ${ }^{9}$ Charité - Universitätsmedizin Berlin, corporate member of Freie Universität Berlin, Humboldt-Universität zu Berlin, and Berlin Institute of Health, Department of Anesthesiology and Surgical Intensive Care, Berlin, Germany. ${ }^{10}$ School of Immunology and Microbial Science, Kings College London. Guy's and St Thomas' NHS Foundation Trust, ICU Support Offices, St Thomas' Hospital, London, UK. "Department of Surgical Sciences and Central Intensive Care Unit, Institute of Clinical Sciences, Sahlgrenska Academy, University of Gothenburg, Gothenburg, Sweden. ${ }^{12}$ Department of Anesthesia, Operation, and Intensive Care; Institute of Clinical Sciences, Sahlgrenska Academy, University of Gothenburg, Gothenburg, Sweden. ${ }^{13}$ Department of Anesthesiology and Intensive Care Medicine, Institute of Clinical Sciences, Sahlgrenska Academy, University of Gothenburg, Gothenburg, Sweden. ${ }^{14}$ Department of Intensive Care Medicine, Division of Anesthesiology, Intensive Care and Emergency Medicine, University Medical Center Utrecht, Utrecht University, Utrecht, The Netherlands. ${ }^{15}$ Humanitas

Clinical and Research Center, Humanitas University, Milan, Italy.

Received: 17 June 2020 Accepted: 20 July 2020

Published online: 05 August 2020

\section{References}

1. Alhazzani W, Møller MH, Arabi YM, et al. Surviving Sepsis Campaign: guidelines on the management of critically ill adults with Coronavirus Disease 2019 (COVID-19). Intensive Care Med Published online March 28, 2020:1-34. doi:https://doi.org/10.1007/s00134-020-06022-5.

2. Bauchner $\mathrm{H}$, Fontanarosa PB. Randomized clinical trials and COVID-19: managing expectations. JAMA Published online May 4, 2020. doi:https://doi. org/10.1001/jama.2020.8115.

3. Sprung CL, Ricou B, Hartog CS, et al. Changes in end-of-life practices in European intensive care units from 1999 to 2016. JAMA. 2019;322(17):1-12. https://doi.org/10.1001/jama.2019.14608.

4. Bhimraj A, Morgan RL, Shumaker AH, et al. Infectious diseases Society of America guidelines on the treatment and management of patients with COVID-19. Clin Infect Dis Off Publ Infect Dis Soc Am Published online April 27, 2020. doi:https://doi.org/10.1093/cid/ciaa478.

5. Aziz S, Arabi YM, Alhazzani W, et al. Managing ICU surge during the COVID19 crisis: rapid quidelines. Intensive Care Med Published online June 8, 2020. doi:https://doi.org/10.1007/s00134-020-06092-5.

6. Helms J, Severac F, Merdji H, Anglés-Cano E, Meziani F. Prothrombotic phenotype in COVID-19 severe patients. Intensive Care Med. Published online May 20, 2020:1-2. doi:https://doi.org/10.1007/s00134-020-06082-7.

7. Azoulay E, Zafrani L, Mirouse A, Lengliné E, Darmon M, Chevret S. Clinical phenotypes of critically ill COVID-19 patients. Intensive Care Med Published online May 28, 2020. doi:https://doi.org/10.1007/s00134-020-06120-4.

\section{Publisher's Note}

Springer Nature remains neutral with regard to jurisdictional claims in published maps and institutional affiliations.

Ready to submit your research? Choose BMC and benefit from:

- fast, convenient online submission

- thorough peer review by experienced researchers in your field

- rapid publication on acceptance

- support for research data, including large and complex data types

- gold Open Access which fosters wider collaboration and increased citations

- maximum visibility for your research: over $100 \mathrm{M}$ website views per year

At $\mathrm{BMC}$, research is always in progress.

Learn more biomedcentral.com/submissions 